\title{
A case of autoimmune polyglandular syndrome type I
}

\author{
G N Lucas ${ }^{1}$, T G Y R Gunapala ${ }^{2}$, D R Dissanayake ${ }^{3}$
}

Sri Lanka Journal of Child Health, 2002; 31: 64-5

(Key words: Autoimmune polyglandular syndrome type 1, Whitaker syndrome)

\section{Introduction}

Autoimmune polyglandular syndrome (APS) type 1 is also called Whitaker's syndrome ${ }^{1}$ or autoimmune polyendocrinopathy candidiasis ectodermal dystrophy ${ }^{2}$. The major components of APS type 1 are chronic mucocutaneous candidiasis, chronic hypoparathyroidism and autoimmune adrenal insufficiency ${ }^{1}$. To define this syndrome at least two of these diseases have to be present in one individual $^{3}$. The spectrum of disease also includes hypergonadotrophic hypogonadism, insulindependent diabetes mellitus, autoimmune thyroiditis, lymphocytic hypophysitis, pernicious anaemia, chronic atrophic gastritis, malabsorption, chronic active hepatitis, vitiligo, alopecia, ectodermal dystrophy, keratoconjunctivitis, immunological defects (cellular and humoral), asplenia and cholelithiasis $^{2,3,4}$.

\section{Case report}

A seven and a half year old boy was admitted to Lady Ridgeway Hospital in March 1998 with a history of severe vomiting and colicky abdominal pain of 3 days duration and cold extremities of one day duration. There was a history of polydipsia, polyuria, craving for salt and recurrent abdominal pain from the age of 2 years. An exploratory laparotomy had been done for a pelvic abscess at the age of 1 year. The mother noticed white patches over the buccal mucosa at 18 months of age. He was the product of a non-consanguineous marriage.

The height and weight were well below the $3 \mathrm{rd}$ centile. There was hyperpigmentation of the palms, buccal mucosa and surgical scar. The child was moderately dehydrated. There was oral thrush. The blood pressure was $80 / 55 \mathrm{~mm}$ mercury.

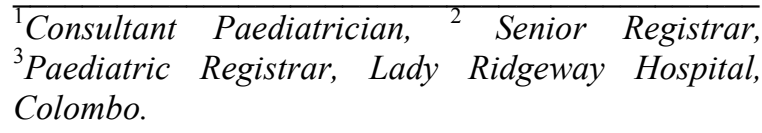

The blood sugar, blood urea and serum creatinine levels were within normal limits. The serum electrolytes showed hyponatraemia $(115 \mathrm{mmol} / \mathrm{L})$, hypochloraemia $(86 \mathrm{mmol} / \mathrm{L})$ and hyperkalaemia $(5 \mathrm{mmol} / \mathrm{L})$. The urinary electrolytes showed an increased excretion of sodium $(128 \mathrm{mmol} / \mathrm{L})$ and chloride $(108 \mathrm{mmol} / \mathrm{L})$. The serum calcium level was normal. The ACTH level was $417 \mathrm{pg} / \mathrm{ml}$ (normal range $0-46 \mathrm{pg} / \mathrm{ml}$ ). The random cortisol level was $13.5 \mathrm{mcg} / \mathrm{dl}$ (basal $5-25 \mathrm{mcg} / \mathrm{dl}$ ). After administration of $0.25 \mathrm{mg}$ ACTH the cortisol level was $22.7 \mathrm{mcg}$ after 30 minutes and $17.2 \mathrm{mcg} / \mathrm{dl}$ after 1 hour. The thyroid function tests (T3, T4 \& TSH) were normal. The ultrasound scan of the abdomen was normal.

A diagnosis of Addison's disease was made and the child was treated with oral hydrocortisone $5 \mathrm{mg}$ twice daily and fludrocortisone $0.025 \mathrm{mg}$ twice daily and followed up in the clinic.

The child was readmitted to the Lady Ridgeway Hospital in June 2001 with a history of carpopedal spasms of 2 weeks duration and fungal infection of the nails accompanied by nail dystrophy of 2 months duration. The height and weight were now on the 50th centile and the hyperpigmentation had disappeared. The blood pressure was 90/60 mm mercury. The serum calcium level was $1.98 \mathrm{mmol} / \mathrm{l}$ (normal 2.12-2.62mmol/l). The serum electrolytes, blood sugar and blood urea were within normal limits. The serum parathyroid hormone level was $8.6 \mathrm{pg} / \mathrm{ml}$ (normal 12-72 pg/ml).

A diagnosis of APS type 1 was made and oral itriconazole, oral calcium lactate and one alpha hydroxylase were given in addition to hydrocortisone and fludrocortisone.

\section{Discussion}

The association between hypoparathyroidism and candidiasis was first noted in $1929^{5}$ and the association of these 2 diseases with adrenal insufficiency was initially reported in $1946^{6}$. In the majority of cases APS type 1 occurs in childhood ${ }^{1,3}$ 
and may occur sporadically or among siblings ${ }^{3,4}$. An association between the clinical expression of the syndrome and genes located in chromosome 21 has been identified ${ }^{7}$. In our patient the diagnosis of APS type 1 was established by the presence of Addison's disease, mucocutaneous candidiasis and hypoparathyroidism. Overall, the 3 main components of APS type 1 are present together in only about one third to one half of the cases ${ }^{2,3}$. The prognosis is guarded since other accompanying diseases continue to appear until at least the 5 th decade ${ }^{2,3}$.

\section{References}

1. Whitaker J, Landing B H, Esselborn V M, Williams R R. The syndrome of familial juvenile hypoadrenocorticism, hypoparathyroidism and superficial moniliasis. Journal of Endocrinology 1956; 16: 1374-87.

2. Ahonen P, Myllarniemi S, Sipila I, Perheentupa J. Clinical variation of autoimmune polyendocrinopathy -candidiasis-ectodermal dystrophy (APECED) in a series of 68 patients. New England Journal of Medicine 1990; 322: 1829-36.
3. Neufeld M, McLaren N K, Blizzard R M. Two types of autoimmune Addison's disease associated with different polyglandular autoimmune (PGA) syndromes. Medicine 1981; 60: 355-62.

4. McIntyre Gass J D. The syndrome of keratoconjunctivitis superficial moniliasis idiopathic hypoparathyroidism and Addison's disease. American Journal of Ophthalmology 1962; 54: 660-74.

5. Thorpe E S, Handley H E. Chronic tetany and chronic mycelial stomatitis in a child aged 4 and half years. American Journal of Diseases in Children 1929; 38: 328-38.

6. Leonard M F. Chronic idiopathic hypoparathyroidism with superimposed Addison's disease in a child. Journal of Clinical Endocrinology and Metabolism 1946; 6: 493-5.

7. Aaltonen J, Bjorses P, Sandkuijl L, Perheentupa J, Peltonen L. An autosomal locus causing autoimmune disease: autoimmune polyglandular disease type 1 assigned to chromosome 21. Nature Genetics 1994; 8: 83-7. 
